\title{
Major causes of organ condemnation and economic loss in cattle slaughtered at Adigrat municipal abattoir, northern Ethiopia
}

\author{
Alembrhan Assefa and Haylegebriel Tesfay \\ Department of Biology (Zoology), \\ College of Natural and Computational Science, Adigrat University P.O. Box 50, Adigrat, Ethiopia \\ Corresponding author: Alembrhan Assefa, e-mail: alembrhanassefa@yahoo.com, Tel.: +2519 10693661 \\ Received: 18-05-2013, Revised: 26-06-2013, Accepted: 27-06-2013, Published online: 08-08-2013
}

doi: $10.14202 /$ vetworld.2013.734-738

How to cite this article: Alembrhan A and Haylegebriel T (2013) Major causes of organ condemnation and economic loss in cattle slaughtered at Adigrat municipal abattoir, northern Ethiopia, Veterinary World 6(10): 734-738.

\begin{abstract}
Aim: The study was conducted to identify major causes of organs condemnation in cattle slaughtered at Adigrat municipal abattoir and to estimate the direct economic losses.

Material and Methods: A cross sectional active abattoir survey, which involves both ante mortem and post mortem examinations, was conducted on 745 cattle from October 2012 to April 2013, and two years (September 2010 - September 2012) retrospective data on meat inspection records was also collected.

Results: During ante mortem examination, in $114(15.3 \%)$ cattle various types of abnormalities were detected include; lacrimation (3.49\%), pale mucus membrane (3.09\%), nasal discharge (1.88\%), hernia (1.48\%), actinomycosis $(1.34 \%)$, salivation $(1.74 \%)$, lameness $(0.54 \%)$, emaciation $(0.41 \%)$, depression $(0.41 \%)$, blindness $(0.41 \%)$, local swelling $(0.27 \%)$ and rough hair coat $(0.27 \%)$. Postmortem examination revealed that $131(17.58 \%)$ liver, $61(8.19 \%)$ lungs, $9(1.21 \%)$ kidneys and $2(0.27 \%)$ hearts were condemned due to various causes. Fasciolosis $(9.26 \%)$ was the main cause of liver condemnation followed by hydatid cyst $(3.62 \%)$ and cysticercus bovis $(2.55 \%)$, respectively. The major causes of lung condemnation were hydatid cyst, emphysema and pneumonia accounting for 5.1, 1.61 and 1.07\%, respectively. Hydronephrosis and cysticercus bovis were the major causes of kidney and liver condemnation with rate of 0.94 and $0.27 \%$, respectively. Totally about 19,910.0 Ethiopian birr (1,083.83 USD) was lost from organs condemnation during the active abattoir survey. From the retrospective data it was observed that liver and lung were the most condemned organs with condemnation rate of 17.72 and $7.53 \%$, respectively. The major causes of organ condemnation were hydatid cyst (11.52\%), cirrhosis (4.97\%), fasciolosis $(4.35 \%)$, cysticercus bovis $(4.12 \%)$ and hydronephrosis $(1.21 \%)$, respectively. Consequently, the overall direct economical loss during the two years was estimated to be 83,890.0 Ethiopian birr (4,566.68 USD).
\end{abstract}

Conclusion: The results identified various causes of organ condemnation and their economic importance in the area. Therefore, it is necessary to establish appropriate strategy for prevention and control.

Key words: abattoir survey, cattle, cause of organ condemnation, economic loss, retrospective study.

\section{I ntroduction}

Parasitic diseases are considered as a major health problem and cause a significant economic loss in countries where livestock production is an important segment of the agricultural practice. Developing countries have about two third of the world's livestock population but their meat and milk production is less than a third of the world [1]. Ethiopia has large livestock population in Africa with an estimated of $44,318,877$ cattle, 23,619,720 sheep and 23,325,113 of goats [2]. However, there are constraints that hindered the potential of livestock production include; traditional management system, limited genetic potential, lack of appropriate disease control policy and veterinary services. Due to these and related factors, each year significant economic losses result from condemnation of edible organs and carcass were estimated from different abattoirs of the country $[3,4]$.

Copyright: The authors. This article is an open access article licensed under the terms of the Creative Commons Attribution License (http://creativecommons.org/licenses/by/2.0) which permits unrestricted use, distribution and reproduction in any medium, provided the work is properly cited.
Monitoring and other conditions at slaughter house have been recognized as one way of assessing the disease status of cattle [5] and abattoirs played an important role in screening animal products with various abnormalities and diseases that are not fit for human consumption [6, 7]. Major parasitic diseases such as fasciolosis, hydatid cyst, cysticercus bovis and others causes like abscessation and cirrhosis cause a significant economic loss by lowering the productivity of cattle and condemnation of edible organs $[4,8,9]$.

Several studies have been conducted through abattoir survey to determine the prevalence and economic loss resulting from organ condemnation in many abattoirs of Ethiopia including Tigray region [10 - 15]. However, most of the studies were focusing only on specific diseases such as fasciolosis, hydatidosis and cysticercosis bovis. Furthermore, economic loss due various diseases/causes was estimated in some abattoirs of the country $[4,16,17,18,19]$.

Hence, it would be essential to have information on occurrence of various diseases/causes and their economic loss from different parts of the country to establish appropriate strategy for prevention and 
controls. Currently, there is lack of information on occurrence of various diseases/causes and their economical loss due to organ condemnation in Adigrat.

Therefore, the objectives of this study were to identify the major causes of organ condemnation and to estimate direct economic loss due to organ condemnation at Adigrat municipal abattoir.

\section{Materials and Methods}

Study area: The study was conducted in eastern zone of Tigray, Northern part of Ethiopia at Adigrat municipal abattoir. Adigrat town is located in Tigray regional state of Ethiopia, which is about $921 \mathrm{~km}$ far from Addis Ababa and $115 \mathrm{~km}$ from Mekelle city, the capital city of Tigray regional state. It is located at altitudinal ranges from 2000-3000 meter above sea level and geographically it located $014^{\circ} 16^{\prime} 34^{\prime \prime} \mathrm{N}$ latitude and $039^{\circ} 27^{\prime} 51$ "E longitude. It has different agro-ecological areas namely sub moist dry, sub moist cool and sub dega. The annual rain fall ranges from $400-600 \mathrm{~mm}$ and the minimum and maximum temperature ranges from $6-21.8^{0} \mathrm{c}$. Its maximum rain fall occurs from June up to September. Agriculture is the main occupation of the population of the area. The agricultural activities are mainly mixed type with cattle rearing and crop production under taken side by side [20].

Study animals: The study animals were cattle brought to the abattoir for slaughter from different districts around Adigrat town.

Study design: The study was conducted through two study designs involving both active abattoir survey and retrospective study.

Active abattoir survey: A cross sectional study was conducted from October 2012 to April 2013 to identify the major causes of organ condemnation and to estimate the direct economic loss due to organ condemnation in cattle slaughtered at Adigrat municipal abattoir. A total of 745 cattle were examined by ante mortem and postmortem examinations using standard examination procedures. The study animals were selected using simple random sampling method.

During the ante mortem examination each of study animal was identified based on the enumerate marks on their body marked before slaughter and their general behavior, signs of disease, nutritional status, cleanliness and any type of abnormalities were recorded [21]. Judgment was also done based on the procedure given by FAO [22]. Postmortem examination was conducted through visualization inspection, palpation and systematic incision of each visceral organ particularly the liver, lung, heart and kidney for the presence of cysts, various adult parasites and other abnormalities [23].

Retrospective abattoir study: A retrospective study was conducted using the postmortem meat inspection records of the abattoir from September 2010 to September 2012. Data was obtained by help of an experienced team of veterinarians and information collected included number of cattle slaughtered, type and number of condemned organs and causes for each condemnation.

Assessment of direct economic loss: Total number of cattle slaughtered, average current local market price and number of each condemned organ were used to estimate the economic loss represented by the cause related condemnations over the study period. Average current local market price of each organ was obtained from the butcheries in Adigrat town.

Statistical analysis: Collected data were entered and stored in to Microsoft excel and analyzed by statistical methods using STATA 11 [24]. Descriptive statistics was used to determine the level of organ condemnation defined as the proportion of condemned organs to the total number of organs examined.

\section{Results}

Active abattoir survey: Out of 745 cattle subjected to ante mortem examination, in $114(15.3 \%)$ cattle various types of abnormalities were detected include; lacrimation, pale mucus membrane, nasal discharge, hernia, actinomycosis, salivation, lameness, emaciation, depression, blindness, local swelling and rough hair coat (Table-1).

Table-1. Abnormalities encountered during ante mortem examination at Adigrat abattoir

\begin{tabular}{lcc}
\hline Abnormalities & No. of infected animal & Percentage \\
\hline Hernia & 11 & 1.48 \\
Lacrimation & 26 & 3.49 \\
Lameness & 4 & 0.54 \\
Actinomycosis & 10 & 1.34 \\
Nasal discharge & 14 & 1.88 \\
Depression & 3 & 0.41 \\
Salivation & 13 & 1.74 \\
Local swelling & 2 & 0.27 \\
Pale mucus membrane & 23 & 3.09 \\
Blindness & 3 & 0.41 \\
Emaciation & 3 & 0.41 \\
Rough hair coat & 2 & 0.27 \\
Total & 114 & 15.3 \\
\hline
\end{tabular}

During postmortem examination, out of the total examined organs, 131 (17.58\%) liver, 61 (8.19\%) lungs, $9(1.21 \%)$ kidneys and $2(0.27 \%)$ hearts were condemned due to various causes (Table-2). Fasciolosis $69(9.26 \%)$ was found to be the main cause of liver condemnation followed by hydatid cyst 27 (3.62\%) and cysticercus bovis 19 (2.55\%), respectively. The major causes of lung condemnation were hydatid cyst; emphysema and pneumonia accounting for 5.1, 1.61 and $1.07 \%$, respectively. Hydronephrosis and Cysticercus bovis were the major causes of kidney and liver condemnation with rate of $7(0.94 \%)$ and 2 $(0.27 \%)$, respectively (Table- 2 ).

Retrospective abattoir study: A retrospective data of 3055 cattle slaughtered was collected from September 2010 to September 2012 and it was observed that liver $(17.72 \%)$ was the most condemned organ followed by lung, heart and kidney with condemnation rate of $7.53 \%$, 
Table-2. Causes, percentage of organ condemnation and economic losses analysis at Adigrat abattoir

\begin{tabular}{lccc}
\hline Condemned organ & Cause & No. (\%) organ condemned & Loss money (Ethiopian birr) \\
\hline Liver & Fasciolosis & $69(9.26 \%)$ & 9660.0 \\
& Hydatid cyst & $27(3.62 \%)$ & 3780.0 \\
& Cysticercus bovis & $19(2.55 \%)$ & 2660.0 \\
& Cirrhosis & $15(2.01 \%)$ & 2100.0 \\
Lung & Calcification & $1(0.13 \%)$ & 140.0 \\
& Total & $131(17.58 \%)$ & $18,340.0$ \\
& Hydatid cyst & $38(5.1 \%)$ & 760.0 \\
& Emphysema & $12(1.61 \%)$ & 240.0 \\
Kidney & Pneumonia & $8(1.07 \%)$ & 160.0 \\
& Abscessation & $3(0.40 \%)$ & 60.0 \\
Heart & Total & $61(8.19 \%)$ & $1,220.0$ \\
& Hydronephrosis & $7(0.94 \%)$ & 210.0 \\
Grand total & Hydatid cyst & $2(0.27)$ & 60.0 \\
\hline
\end{tabular}

Table-3. Retrospective data on causes, percentage of organ condemnation and economic loss at Adigrat abattoir (September 2010- September 2012).

\begin{tabular}{lccc}
\hline Condemned organ & Cause & No. (\%) organ condemned & Loss money (Ethiopian birr) \\
\hline Liver & Cirrhosis & $152(4.97 \%)$ & 21280.0 \\
& Fasciolosis & $133(4.35 \%)$ & 18620.0 \\
& Cysticercus bovis & $113(3.70 \%)$ & 15820.0 \\
& Hydatid cyst & $121(3.96 \%)$ & 16940.0 \\
& Abscessation & $8(0.26 \%)$ & 1120.0 \\
& Hepatitis & $5(0.16 \%)$ & 700.0 \\
Calcification & $10(0.33 \%)$ & 1400.0 \\
Lung & Total & $542(17.72 \%)$ & $75,880.0$ \\
& Hydatid cyst & $200(6.55 \%)$ & 4000.0 \\
& Abscessation & $3(0.1 \%)$ & 60.0 \\
& Emphysema & $15(0.49 \%)$ & 300.0 \\
Kidney & Pneumonia & $12(0.39 \%)$ & 240.0 \\
& Total & $230(7.53 \%)$ & $4,600.0$ \\
& Hydronphrosis & $37(1.21 \%)$ & 1110.0 \\
Heart & Abscessation & $3(0.1 \%)$ & 90.0 \\
& Others & $7(0.23 \%)$ & 210.0 \\
& Total & $47(1.54 \%)$ & 1410.0 \\
Grand total & Hydatid cyst & $31(1.01 \%)$ & 1240.0 \\
& Cysticercus bovis & $13(0.43 \%)$ & 520.0 \\
& Others & $6(0.19 \%)$ & 240.0 \\
& Total & $50(1.64 \%)$ & $2,000.0$
\end{tabular}

$1.64 \%$ and $1.54 \%$, respectively (Table-3). The major causes of organs condemnation were hydatid cyst $(11.52 \%)$, cirrhosis $(4.97 \%)$, fasciolosis (4.35\%), Cysticercus bovis (4.12\%) and hydronephrosis (1.21\%), respectively (Table-3).

Assessment of direct economic loss: The total direct economical loss incurred due to organs condemnation during active abattoir survey was estimated to be 19,910.0 Ethiopian birr (1,083.83USD) (1USD 18.37 Ethiopian birr by the time when the study was conducted). Higher economic losses were encountered mainly due to fasciolosis (9660 Ethiopian birr) and hydatid cyst ( 4600 Ethiopian birr), respectively (Table2 ). From the retrospective study the overall economical loss during two years was estimated to be $83,890.0$ Ethiopian birr (4,566.68 USD) (Table-3).

\section{Discussion}

This study showed that fasciolosis, hydatid cyst, Cysticercus bovis, pneumonia, emphysema, hydronephrosis, cirrhosis, hepatitis, calcification, and abscessation were the major causes of organs condemnation in cattle slaughtered at Adigrat municipal abattoir. This finding is similar with reports from different abattoirs of Ethiopia [4, 16, 17, 18, 19].

Out of the total examined organs $131(17.58 \%)$ liver, $61(8.19 \%)$ lungs, $9(1.21 \%)$ kidneys and 2 $(0.27 \%)$ hearts were condemned due to various causes. The rejection rates of liver in this study was lower than the reports of Yifat et al. [17] from Gondar, Nurit et al. [18] from Kombolcha and Amene et al. [4] from Jimma municipal abattoirs who reported 31.1, 66.55 and $64.4 \%$, respectively. But it was observed higher as compared with studies conducted by Oryan et al. [25] 4.2\% and Hassan et al. [9] 7.9\% from Iran. The rejection rate of lung in this study was lower than reports by Genet et al. [3] of $19.68 \%$ at Gondar, Asmare et al. [19] of 25.8\% at Bahir Dar and Amene et al. [4] of $46.2 \%$ at Jimma municipal abattoirs. The rejection rates of kidneys and hearts in this study are lower than the rejection rate (i.e. 18 and $11 \%$ ) that reported by Amene et al. [4] from Jimma and (5.77 and $3.71 \%$ ) by Shagaw et al. [16] from Mekelle abattoirs. Variations in the rejection rate of organs probably due to differences in agro-ecological conditions that favorable to the parasites, livestock management system and 
prevalence of diseases at the different study sites.

This study showed that fasciolosis $(9.26 \%)$ was the main cause of liver condemnation. This finding was relatively in agreement with the previous studies conducted by Mihreteab et al. [11] and Dechassa et al. [26] at Adwa and Jimma municipal abattoirs, respectively. But it was lower than reports at Jimma abattoir by Tadelle and Worku [27], at Gondar by Genet et al. [3] and at Kombolcha by Nurit et al. [18] who reported $63.89,48.5$ and $36.06 \%$, respectively. Liver condemnation due to hydatid cyst $(3.62 \%)$ in the present study was lower than studies conducted by Gebretsadik [28] who reported $12.56 \%$ from Tigray, by Mihret et al. [15] 33.33\% from Dire Dawa, by Zelalem et al. [29] $31.7 \%$ from Addis Ababa and Asmare et al. [19] 10.2\% from Bahir Dar municipal abattoirs. Also cysticercus bovis was observed at a rejection rate of liver $2.55 \%$ which is higher than reports by Ashwani and Gebretsadik [30] who reported $0.26 \%$ rate of rejection from Tigray and Amene et al. [4] 0.22\% from Gondar and Gholam et al. [31] 0.13\% from Iran.

Hydatid cyst found to be the main cause of lung condemnation with rate of $5.1 \%$ which is much lower than reports from Mekelle, Ambo, Nekemte and Dire Dawa abattoirs by Gebremeskel and Kalayou [32], Endrias et al. [33], Fufa et al. [34] and Mihret et al. [15], respectively but higher than the rejection rate reported by Fredrick et al. [35] from Zambia. In this study rejection rate of lung due to emphysema was $1.61 \%$ which is in agreement with the rate reported by Yifat et al. [17] $1.5 \%$ from Gondar but lower than the rate reported by Amene et al. [4] 6.77\% from Jimma and Genet et al. [3] 10.5\% from Gondar abattoirs. Other cause of lung condemnation was pneumonia and it was observed at a rate of $1.07 \%$ which is in agreement with reports by Amene et al. [4] at Jimma, and Yifat et al. [17] at Gondar abattoirs and lowers than the report by Genet et al. [3] who reported $12.45 \%$ in cattle slaughtered from Gondar abattoir.

The present study also showed that higher kidney was condemned due to hydronephrosis. This result is in agreement with previous studies by Yifat et al. [17] and Amene et al. [4] from Gondar and Jimma abattoirs, respectively. However, according to Genet et al. [3] higher rejection rate of kidney was due to hydatid cyst and pyonephritis. The main cause of heart rejection in this study was Cysticercus bovis $(0.27 \%)$ which is relatively similar with previous studies by Bekelle et al. [36] and Amene et al. [4] who reported 0.8\% and $0.22 \%$, respectively and it was lower than report by Ashwani and Gebretsadik [30] in cattle slaughter from Tigray. However, Genet et al. [3] from Gondar abattoir reported that pericarditis, Abscessation and hydatid cyst were the most common causes of heart condemnation. The differences in the rejection rate of organs with related to different causes may be due to the differences in the prevalence of the disease and variation in animal management systems at different study sites.

From the retrospective study, livers and lungs were the most condemned organs. This finding was relatively in agreement with previous report by Endalew and Nurraddis [14] who reported (11.25 and 7\%) from North Gondar and lower than studies conducted by Shagaw et al. [16] who reported 51.95 and $29.54 \%$ from Mekelle, by Raji and Parandeh [37] 60.81 and $40.42 \%$ from Iran and Fredrick et al. [35] 47.6 and $51.2 \%$ from Zambia.

The total direct economic loss incurred due to condemnation of organs in active abattoir survey was 19,910.0 Ethiopian birr (1,083.83 USD). Similarly, in Gondar Elfora abattoir 18,973.22 Ethiopian birr was reported [17]. However, 39,490.0 and 172, 664.09 Ethiopian birr were reported from Gondar and Jimma municipal abattoirs, respectively [3,4]. Higher economical loss in this study was encountered mainly due to fasciolosis and hydatid cyst, which account 9660 and 4600 Ethiopian birr, respectively. This economic loss due to fasciolosis and hydatid cyst was lower than the report by Amene et al. [4] from Jimma municipal abattoir who reported 125,842.0 and 27,207.3 Ethiopian birr, respectively. From the retrospective study the overall economical loss during two years was $83,890.0$ Ethiopian birr (4,566.68 USD). This result was lower than the retrospective reports conducted by Gholam et al. [31] and Hassan et al. [9] from Iran who reported 8.2 million and 13,880 USD, respectively. Variations in the amount of economic lost in different abattoirs probably due to the differences in the prevalence of diseases, rejection rate of organs, slaughtering capacity of the abattoirs, local market price of organs and management of animals.

\section{Conclusions}

The present study revealed that fasciolosis, hydatid cyst, Cysticercus bovis, pneumonia, emphysema, hydronephrosis, cirrhosis, hepatitis, calcification and abscessation were the major causes of organs condemnation in cattle in Adigrat municipal abattoir resulting in considerable economical loss in cattle production. Eradication of these diseases requires cooperation between the public health and official veterinary authorities. Public health education to avoid eating of raw meat, proper disposal of condemned organs, cattle management system, treatment of animals with anti-helminthes drugs and grazing management of animals during dry season to avoid access of the animals to the parasites eggs are important. In addition to this proper and detail meat inspection at the abattoir are also recommended.

\section{Authors' contributions}

AA designed the study, drafted and revised the manuscript. HT examined the sample, analysed the data and edited the manuscript. Both authors read and approved the final manuscript.

\section{Acknowledgments}

The authors would like thank to the abattoir veterinarian team for their invaluable cooperation 
during data collection and allowing the abattoir records. In addition, all contributions are also greatly acknowledged. This study was conducted with the willingness of authors and abattoir veterinarian team but there was no institution or organization that contributing financial fund for this study.

\section{Competing interests}

The authors declare that they have no competing interests.

\section{References}

1. Food and Agriculture Organization, (1995) Manual of meat inspection for developing countries. FAO. Animal Production and Health.

2. Central Statistical Authority (CSA) (2008) Federal Democratic Republic of Ethiopia, Agricultural Sample Enumeration Statistical Abstract.

3. Genet, M., Tadesse, G., Basaznew, B. and Mersha, C. (2012) Pathological Conditions Causing Organ and Carcass Condemnation and Their Financial Losses in Cattle Slaughtered in Gondar, Northwest Ethiopia. African J. Basic \&Appl.Sci., 4 (6): 200-208.

4. Amene, F., Eskindir, L. and Dawit, T. (2012) Cause, Rate and Economic Implication of Organ Condemnation of Cattle Slaughtered at Jimma Municipal Abattoir, Southwestern Ethiopia. Global Veterinaria, 9 (4): 396-400.

5. Mellau, L., Longa, H. and Karimuribu, E. (2010) A Slaughter house survey of liver lesion in slaughter cattle, sheep and goats at Arusha, Tanzania. J. Vet. Sci., 3: 179-188.

6. Vanlontestijn, J. (1993) Integrated quality. Meat safety: A new approach. Meats Focus International, 2:123-128.

7. Alton, G., Lpeah, D., Bateman, K., Mc Nab, W. and Berk, O. (2010) Factors associated with whole condemnation rates in provincially inspected abattoir in Ontario 2001-2007: Implication for food animal syndromic surveillance. $B M C$ Vet. Res., 6: 42.

8. Biu, A. and Adindu, J. (2004) The prevalence of bovine hydatidosis in Maiduguri, Nigeria. J. Life and Environmental Sci., 6(2): 360-362.

9. Hassan, B., Mohammad, A. and Mehrab, K. (2012) A retrospective study of abattoir condemnation due to parasitic infections: economic importance in Ahwaz, southwestern Iran. J. Parasitol., 98(5): 954-957.

10. Gebretsadik, B., Gebrehiwot, T., Habtom, K. and Negus, A. (2009) Prevalence and economic significance of fasciolosis in cattle in Mekelle area of Ethiopia. Trop. Anim. Health Prod., 41:1503-1504.

11. Mihreteab, B., Haftom, T. and Yehenew, G. (2010) Bovine Fasciolosis: Prevalence and its economic loss due to liver condemnation at Adwa Municipal Abattoir, North Ethiopia. EJAST, 1(1): 39-47.

12. Hussein, B., Ketema, T., Birhanu, S., Desalegn, W., Bemnet, A. and Afework, K. (2011) Bovine Cysticercosis in Cattle Slaughtered at Zeway Municipal Abattoir: Prevalence and its Public Health Importance. J. Veterinary Sci. Technol., 2: 108.

13. Dawit, T., Tewodros, S. and Tilaye, D. (2012) Public Health and Economic Significance of Bovine Cysticercosis in Wolaita Soddo, Southern Ethiopia. Global Vet., 9 (5): 557-563.

14. Endalew, D. and Nuradddis, I. (2013) Prevalence and Economic Importance of Hydatidosis in Cattle Slaughtered at North Gonder Elfora Abattoir. Europ. J. Appl. Sci., 5 (1): 29-35.

15. Miheret, M., Biruk, M., Habtamu, T. and Ashwani, K. (2013) Bovine Hydatidosis in Eastern Part of Ethiopia. MEJS, 5(1): 107-114.

16. Shegaw, S., Ashwani, K. and Kassaw, A. (2009) Organs condemnation and economic loss at Mekelle municipal abattoir, Ethiopia. J. Haryana Veterinarian, 48:17-22.

17. Yifat, D., Gedefaw, D. and Desie, S. (2011) Major Causes of Organ Condemnation and Financial Significance of Cattle Slaughtered at Gondar Elfora Abattoir, Northern Ethiopia. Global Veterinaria, 7 (5): 487-490.
18. Nurit, M., Zerihun, H. and Serkalem, M. (2012) Major Cause of Liver Condemnation and Associated Financial Loss at Kombolcha Elfora Abattoir, South Wollo, Ethiopia. Europ. J.Appl. Sci., 4 (4): 140-145.

19. Asmare, A., Biniyam, A. and Mersha, C. (2012) Major Causes of Lung and Liver Condemnation and Financial Impact in Cattle Slaughter at Bahir Dar Municpial Abattior. African J. Basic \& Appl. Sci., 4 (5):165-171.

20. Ganta Afeshum Bureau of Agriculture and Natural Resource (GBOANR) (2010). Report.

21. Gracey, J. (1986) Meat Hygiene. 8th ed. London. Baillere Tindall, pp, 123-265.

22. Food and Agriculture Organization (1994). Manual of meat inspection for developing countries. FAO. Animal Production and Health, pp, 119-359.

23. Getaw, A., Beyene, D., Ayana, D., Megersa, B. and Abunna, F. (2010) Hydatidosis: prevalence and its economic importance in ruminant slaughtered at Adama municipal abattoir, Central Oromia, Ethiopia. Acta Trop., 113:221-225.

24. Stata Corporation (2007). STATA version 11 for windows, 4905 Lakeway Drive, College Station, Texas 77845, USA.

25. Oryan, A., Goorgipour, S., Moazeni, M. and Shirian, S. (2012) Abattoir prevalence, organ distribution, public health and economic importance of major metacestodes in sheep, goats and cattle in Fars, southern Iran. Trop. Biomed., 29(3): 349-359.

26. Dechasa, T., Anteneh, W. and Dechasa, F. (2012) Prevalence, gross pathological lesions and economic losses of bovine fasciolosis at Jimma Municipal Abattoir, Ethiopia. J. Vet. Med.Anim. Health, 4(1): 6-11.

27. Tadele, T. and Worku, T. (2007) Prevalence and Economic Significance of Bovine Fasciolosis at Jimma, Abattoir, Ethiopia. The Internet J. Vet. Med., $3: 15$.

28. Gebretsadik, B. (2009) Abattoir survey on cattle hydatidosis in Tigray Region of Ethiopia. Trop. Anim. Health Prod., 41: 1347-1352.

29. Zelalem, F., Tadele, T., Zelalem, N., Chanda, M. and Nigatu, Kebede. (2012) Prevalence and characterization of hydatidosis in animals slaughtered at Addis Ababa abattoir, Ethiopia. J. Parasitol. Vector Biol., 4(1): 1-6.

30. Ashwani, K. and Gebretsadik, B. (2008) Occurrence of cysticercosis in cattle of parts of Tigray region of Ethiopia. $J$. Haryana Veterinarian, 47: 88-90.

31. Gholam, R., Eshrat, B. and Morteza, R. (2012) Liver condemnation and economic losses due to parasitic infections in laughtered animals in Iran. J. Parasitic Dis., DOI; 10.1007/s12639-012-0172-6.

32. Gebremeskel, B. and Kalayou, S. (2009) Prevalence, viability and fertility study of bovine cystic echinococcosis in Mekelle city, Northern Ethiopia. Revue méd. Vét., 160 (2): 9297.

33. Endrias, Z., Yechale, T. and Assefa, M. (2010) Bovine Hydatidosis in Ambo Municipality Abattoir, West Shoa, Ethiopia. Ethiop. Vet. J., 14 (1): 1-14.

34. Fufa, A., Desta, A., Alemayehu, R., Bekele, M. and Etana, D. (2011) Major Metacestodes in cattle slaughtered at Nekemte Municipla Abattoir, Western Ethiopia: Prevalence, Cyst Viability, Organ Distribution and Socio Economic Implications. Biomirror, 2(10): 1-7.

35. Fredrick, B., King, S., John, B., Musso, M. and Hetron, M. (2012) A Cross-Sectional Study Investigating Cystic Hydatidosis in Slaughtered Cattle of Western Province in Zambia. ISRN Parasitology, 2013: 1-9.

36. Bekele, M., Eliyas, T., Alemayehu, R., Rahmeto, A. and Fufa, A. (2010) Bovine cysticercosis in Cattle Slaughtered at Jimma Municipal Abattoir, South western Ethiopia: Prevalence, Cyst viability and Its Socio-economic importance. Veterinary World, 3 (6): 257-262.

37. Borji, H. and Parandeh, S. (2010) Abattoir condemnation of meat because of parasitic infection, and its economic importance: results of a retrospective study in north-eastern Iran. Ann Trop. Med. Parasitol., 104 (8):641-647.

$* * * * * * * *$ 